\title{
Gender and the hygiene hypothesis
}

\author{
Sharyn Clough* \\ Philosophy, Oregon State University, Hovland Hall, Corvallis, OR 97331, USA
}

\section{A R T I C L E I N F O}

\section{Article history:}

Available online 9 December 2010

\section{Keywords:}

Gender

Hygiene hypothesis

Immune disorders

Feminist theory

Epidemiology

\begin{abstract}
A B S T R A C T
The hygiene hypothesis offers an explanation for the correlation, well-established in the industrialized nations of North and West, between increased hygiene and sanitation, and increased rates of asthma and allergies. Recent studies have added to the scope of the hypothesis, showing a link between decreased exposure to certain bacteria and parasitic worms, and increased rates of depression and intestinal autoimmune disorders, respectively. What remains less often discussed in the research on these links is that women have higher rates than men of asthma and allergies, as well as many auto-immune disorders, and also depression. The current paper introduces a feminist understanding of gender socialization to the epidemiological and immunological picture. That standards of cleanliness are generally higher for girls than boys, especially under the age of five when children are more likely to be under close adult supervision, is a robust phenomenon in industrialized nations, and some research points to a crosscultural pattern. I conclude that, insofar as the hygiene hypothesis successfully identifies standards of hygiene and sanitation as mediators of immune health, then attention to the relevant patterns of gender socialization is important. The review also makes clear that adding a feminist analysis of gender socialization to the hygiene hypothesis helps explain variation in morbidity rates not addressed by other sources and responds to a number of outstanding puzzles in current research. Alternative explanations for the sex differences in the relevant morbidity rates are also discussed (e.g., the effects of estrogens). Finally, new sources of evidence for the hygiene hypothesis are suggested in the form of cross-cultural and other natural experiments.
\end{abstract}

(c) 2010 Elsevier Ltd. All rights reserved.

\section{Introduction}

What has become known as the "hygiene hypothesis" was offered as an explanation for the correlation between increased patterns of hygiene and sanitation, and increased incidence of allergies and asthma (Strachen, 1989). Especially in the industrialized nations of the North and West, it is hypothesized, lower rates of exposure to certain kinds of allergens, bacteria and other microorganisms have had unintended, negative consequences for immune health. In the words of neuroscientists Rook and Lowry, as "a consequence of diminished exposure," especially in childhood, to a variety of micro-organisms once prevalent in the human evolutionary past, populations in developed countries have a "lack of appropriate levels of immunoregulatory pathways" (Rook \& Lowry, 2008, 150).

As discussed in Jackson's Allergy: The History of a Modern Malady (2006), the link between the historically recent rise in incidence

\footnotetext{
* Corresponding author. Tel.: +1541 7379801.

E-mail address: sharyn.clough@oregonstate.edu.
}

and prevalence of allergies and asthma, on the one hand, with particular geographical and environmental locations (specifically urban, industrialized nations of the North and West), on the other, has been well documented by epidemiologists and public-health practitioners for over 100 years. In accounting for this link, the hygiene hypothesis competes with a number of other explanatory mechanisms, such as new patterns of ragweed pollen dispersal, the relatively recent rise in environmental toxins and air pollution, as well as the proliferation of dust mites caused by increases in the installation of wall-to-wall carpeting, the move to more energy efficient windows (with the concomitant decrease in fresh air circulation) and other recent trends in Western urban household design (these competing hypotheses are discussed by Jackson, 2006, pp. 148-184).

While these competing factors have no doubt exacerbated cases of allergies and asthma for many people, they do not yet form a robust epidemiological account of the morbidity patterns of interest (Jackson, 2006). As the most recent contender, the hygiene hypothesis is still under investigation, but it has proven to be compelling, and more recent support has come in the form of increased explanatory scope: in addition to allergies and asthma, 
a variety of auto-immune disorders have now been linked to the hypothesis. For example, it turns out that populations in those less industrialized nations of the rural South and East that are still regularly exposed to certain parasitic worms (helminths), also have a lower incidence and prevalence of chronic inflammatory diseases such as Crohn's, than do populations in industrialized nations of the North and West that are not regularly exposed (Elliott, Summers, \& Weinstock, 2007). In India, the incidence of Crohn's, while lower than in nations of the North and West, is on the increase, reliably tracking rates of industrialization and sanitation (DeSai \& Gupta, 2005).

The hygiene hypothesis has also been suggested as a further piece of the causal story in some cases of depression (Rook \& Lowry, 2008), although, as I discuss below, the documentation for this link is not as strong as that between the hygiene hypothesis and the other pathologies mentioned. Briefly, the current literature shows that some kinds of depression can be linked to failures of immune regulation, and higher levels of proinflammatory cytokines (signaling molecules produced by the immune system) (Rook \& Lowry, 2008).

One common denominator that has received no critical attention by hygiene hypothesis researchers however, is that in nations of the industrialized North and West, at least, women are overrepresented in all the relevant clinical populations. Women have higher rates than men of asthma, allergies, many auto-immune disorders (Bird \& Rieker, 1999, 2008), as well as depression (Hankin \& Abramson, 2001). The "feminization" of these diagnostic categories has been well acknowledged by clinicians who treat and study these illnesses, but not by the immunologists and epidemiologists involved in studying the hygiene hypothesis.

It is surprising that hygiene hypothesis research lacks attention to sex differences in morbidity rates. Gender and sex differences have become increasingly salient categories of analysis for immunologists and epidemiologists more generally (e.g., Krieger, 2003). And in the case of the hygiene hypothesis in particular, sex differences are related to the research findings in important ways, or so I shall argue.

Returning briefly to the clinical picture, it is important to note that while clinicians have noticed the sex differences in the populations they treat and study, their own explanatory lapse has come in the form of a trend towards reductionistic, biomedical explanations for these differences that put the focus on physiological, hormonal, and genetic accounts, with little to no attention paid to the ways these same processes are affected by complex environmental and social factors, such as patterns of hygiene and sanitation, and the interweaving effects of gender, race and economic hierarchies (see Barker, 2005, esp. ch. 2; Bird \& Rieker, 2008; Epstein, 2007 for a critical discussion of the trend towards the reductionistic biomedicalization of these diagnoses).

For example, sex hormones, such as the family of estrogens, have been hypothesized to account for the differential rates of autoimmune disorders in women compared to men, as have a variety of genetic phenomena, such as X-chromosome mosaicism (for a critical discussion of these particular biomedical approaches as they relate to immune health in women, see Beeson, 2004 and Richardson, 2008). Similarly, sex hormones have featured in explanations for the higher rates of depression in women (Altemus, 2006). It should be noted that compared to the literature on immune disorders, the literature on sex differences in depression includes far more attempts, especially by feminist clinicians and researchers, to examine the role of more complex social factors such as the social and cognitive effects of sexism (Kuehner, 2003; Nolen-Hoeksema, 2001). The fact remains, however, that in each attempt, biomedical or otherwise, to account for the differences in the relevant morbidity rates between women and men, a significant amount of variation is left unexplained.
This is precisely the explanatory gap that the hygiene hypothesis is suited to address, especially when a feminist understanding of the gendered socialization of children is added to the epidemiological and immunological picture. In industrialized nations of the North and West, at least, standards of cleanliness are generally higher for girls than boys, especially for young children who are more likely to be under close adult supervision (e.g., Caldera, Huston, \& O'Brien, 1989).

In what follows, I review the case for the hygiene hypothesis. I argue that, insofar as the hygiene hypothesis successfully identifies standards of hygiene and sanitation as mediators of immune health, then, properly augmented by feminist analyses of the gendered standards of cleanliness in children, the hypothesis can account for the unexplained variation in the relevant morbidity rates between men and women. The augmented hygiene hypothesis also responds to a number of outstanding puzzles in current epidemiological and immunological research on allergens and parasites. I conclude by presenting new sources of evidence for the hygiene hypothesis in the form of cross-cultural and other natural experiments involving gender differences.

\section{The hygiene hypothesis}

\section{Germs, allergies, and asthma}

Industrialized nations of the North and West have experienced increasing rates of asthma and allergies. In a recent study, Maziak et al., note that "There is a wide consensus that asthma and allergies are witnessing a rising trend among children in Western societies. In some Western countries asthma and allergies have reached alarming proportions, affecting up to one-third of children within the general population" (Maziak et al., 2003, p. 572).

This increase has been explained by appealing to increased standards and practices of hygiene and sanitation. As Strachen concluded in his brief but seminal study: "Over the past century declining family size, improvements in household amenities, and higher standards of personal cleanliness have reduced the opportunity for cross infection in young families. This may have resulted in more widespread clinical expression of atopic [allergic 'hypersensitivity'] disease, emerging earlier in wealthier people, as seems to have occurred for hay fever" (Strachen, 1989, p. 1260).

Recent experimental support with mice has shown that a variety of allergic responses can be decreased via exposure to a particular bacterium - Mycobacterium vaccae (Ricklin-Gutzwiller et al., 2007; Zuany-Amorim et al., 2002). Support for the hygiene hypothesis also comes from studies of human populations that document the protective effects of farm environments for children (Kilpeläinen, Terho, Helenius, \& Koskenvuo, 2000). Compared to children raised in urban settings, children raised on farms have lower rates of allergic rhinitis and/or conjunctivitis. Kilpeläinen et al., conclude that "environmental exposure to immune modulating agents, such as environmental mycobacteria ... could explain the finding" (Kilpeläinen et al., 2000, p. 201). Exposure to two or more domestic pets has been shown to have a similar protective effect: "exposure to 2 or more dogs or cats in the first year of life was associated with a lower prevalence of allergic sensitization at age 6-7 years" (Ownby, Johnson, \& Peterson, 2002, p. 969). A more recent study of children in the Philippines found that increased exposure to microbes in childhood predicted increased immune health in adulthood (McDade, Rutherford, Adair, \& Kuzawa, 2009).

\section{Parasites and inflammatory diseases}

Eliot, Summers, and Weinstock have theorized that the increase in other immune system malfunctions such as inflammatory-bowel 
disease (IBD) and Crohn's disease may also be related to the hygiene hypothesis (Elliott et al., 2007). They observed that in contemporary urban environments where humans are largely free of contamination by parasitic worms, rates of these sorts of diseases have increased dramatically. In Israel, for example, Zvidi et al. report that "the prevalence rate rose from $25.53 / 100,000$ in 1987 to $65.11 / 100,000$ in 1997, and then to 112.99 in 2007" (Zvidi, Hazazi, Birkenfeld, \& Niv, 2008). Since some parasitic worms seem to have a "calming" effect on the immune system, it seems likely that the trends are related. Indeed, clinical trials have shown that exposure to the eggs of the Trichuris suis whip worm can reduce the severity of symptoms in patients with Crohn's (e.g., Elliott et al., 2007; Erb, 2009; Summers, Elliott, Urban, Thompson, \& Weinstock, 2005).

\section{Bacteria and depression}

The most recent and surprising finding in this collection of studies is that certain sorts of depression might also be explained by the hygiene hypothesis (Lowry et al., 2007; Rook \& Lowry, 2008; Spiga, Lightman, Shekar, \& Lowry, 2006). As I have noted, the documentation for this link is less robust than that between the hygiene hypothesis and the other pathologies mentioned. Neuroscientists Rook and Lowry argue that "depression and anxiety are associated with markers of ongoing inflammation, even without any accompanying inflammatory disorder" (Rook \& Lowry, 2008, p. 150 ) and that one effect of SSRIs (the most-commonly prescribed form of anti-depressant) is to lower the inflammatory response (Rook \& Lowry, 2008, p. 153). Whether the association between depression and clinically significant inflammatory response is a causal association is currently supported by clinical evidence that "proinflammatory cytokines can induce depression" (p. 150, 152) and that in an example of the inverse pattern, cancer patients who were treated with a harmless version of the bacterium $M$. vaccae, reported "higher quality of life," even though the bacterium had no effect on their survival rates from cancer (O'Brien et al., 2004). The relation between "quality of life" and depression is not wellexamined in these studies.

Insofar as lower levels of bacterial loads generally can be linked to the standards and practices of cleanliness and sanitation found in industrialized nations, and insofar as the currently weak link between depression and immune health proves to be accurate, Rook and Lowry expect that depression rates too would differ between industrialized and nonindustrialized nations. There is some data to support their expectation. They write:

Estimates of the incidence of depression in rich industrialized nations are consistently higher than in poor rural nations. Indeed, in young adults (15-29 year olds), the incidence of depression in men in the United States and Canada is estimated to be twice, while that in women is estimated to be three times, that seen in Africa, and within Europe depression tends to be more prevalent in urban than in rural communities (Rook \& Lowry, 2008, p. 153).

Rook and Lowry admit that the data from these latter studies is "fraught with problems in interpretation" (Rook \& Lowry, 2008, p. 153). For example, an examination of the studies they cite (Ayuso-Mateos et al., 2001; Chisholm et al., 2004) reveals that while there has been some success at unifying diagnostic criteria across populations, problems in estimating prevalence and incidence across cultures remain and are well acknowledged (see Horwitz \& Wakefield, 2007 on problems comparing, for example, the diagnostic criteria of the DSM and the ICD).

However, despite the problems in cross-cultural comparisons of this sort, what remains robust is the finding that no matter what population is being sampled, within that population, more women than men satisfy criteria for depression, and this is particularly the case in countries of the industrialized North and West. Additionally, as Bird and Rieker note, "it is now well-established that women's higher rates of depression reflect a real [sex] difference in health, rather than an artifact of help-seeking behavior or willingness to report symptoms" (Bird \& Rieker, 2008, p. 32).

Rook and Lowry do not comment on this difference between women and men within nations of the North and West. They focus instead on the less reliably-documented differences in depression rates across societies, that is, for women and men from industrialized nations of North and West, as compared to women and men of the more rural nations of South and East. As supporters of the hygiene hypothesis, which predicts the latter pattern across societies, it makes sense that they would have nothing to say about the sex differences within societies-in contrast, my augmented hypothesis offers a cogent explanation for these latter sex differences as well, indeed within any society that has differential gender standards in hygiene for girls and boys.

\section{Feminist social science and the hygiene hypothesis}

What is required to make the conceptual link between these sex differences and patterns of hygiene is a feminist analysis of the content of the social roles assigned to boys and girls in societies of the industrialized North and West; an analysis that reveals how masculine gender role assignment, broadly construed, involves an acceptance of playing in dirt and mud for those (typically boys) so assigned. This acceptance does not usually extend to the feminine gender role, broadly construed (a role typically assigned to girls).

I should note one potential limitation of my analysis. While I attend to differentiations in categories of nationality and levels of urbanization, I continue to use the gendered labels "masculine"| "feminine" as if they were unproblematic and exhaustive. While analyses based on two genders will probably capture the relevant variation of interest, epidemiologically-speaking, it is important to acknowledge that a broader discussion of gender identity and gender expression, including (data from) populations of people who are transgender/transsexual, while beyond the scope of this paper, will likely enrich the explanatory account.

As I show below, feminist researchers have documented gendered social expectations regarding cleanliness, as these expectations are reflected in and reinforced by gender differences in children's clothing, participation in sports, and adult supervision of children's play.

\section{Gendered norms of cleanliness}

Feminist-informed sociologists in the industrialized North and West have documented that girls are dressed more often than boys in clothing that is not supposed to get dirty, and that restricts the sorts of movements that would get one dirty in the first place (Martin, 1998). Girls do not participate in sports with the same frequency as boys, and girls more often than boys play indoors (Pomerleau, Bolduc, Malcuit, \& Cossette, 1990). Insofar as many sports, and outdoor play generally, increases the chances for exposure to the micro-organisms found in dirt (and there is abundant evidence to support this, e.g., Lanphear \& Roghmann, 1997), then boys will have greater rates of exposure to these microorganisms than will girls. Finally, parents structure and supervise the play of girls more than that of boys (Caldera et al., 1989), which is likely to result in girls being kept cleaner than boys.

Not surprising, given that girls receive more parental supervision and direction regarding cleanliness than do boys, girls more than boys are taught to police themselves-to be vigilant about 
their appearance and cleanliness. In a 1938 Boston study of the content of preschool children's speech, psychologist Shirley found marked gender differences with respect to the concepts of cleanliness and clothes. She noted that these two concepts are mentioned in conversations "about twice as often by girls as by boys" (Shirley, 1938, p. 336). Even by preschool, traditional strictures about cleanliness have been differentially absorbed by little girls.

While these gender differences in hygiene standards might seem a relic of a distant sexist past, research suggests otherwise. As recently as 1991, research showed that a significant number of students training to be preschool teachers in the UK expected the children in their classes to conform to fairly standard gender roles, including gendered norms of cleanliness. In one study, over $25 \%$ of preschool student teachers "expected boys, but not girls to be reckless, untidy, cheeky, brave, noisy and naughty; and expected girls, but not boys to be tidy, lean, quiet, sensible, obedient, passive and well-behaved" (Sikes, 1991).

Many parents continue to reinforce traditional gendered norms of hygiene in their preschool children, as expressed, for example, in how children are dressed. In a study of American children in a preschool setting (Martin, 1998), one-third of the five-year-old girls came to school in dresses each day. Of relevance to the question of cleanliness, Martin noted that being in a dress limited the girls' "physicality." However, she added, "it is not only the dress itself, but knowledge about how to behave in a dress that is restrictive. Many girls already knew that some behaviors were not allowed in a dress. This knowledge probably comes from the families who dress their girls in dresses" (p. 498). One particular observation of five-year-old girls in Martin's study is worth quoting at length:

Vicki, wearing leggings and a dress-like shirt, is leaning over the desk to look into a "tunnel" that some other kids have built. As she leans, her dress/shirt rides up exposing her back. Jennifer (another child) walks by Vicki and as she does she pulls Vicki's shirt back over her bare skin and gives it a pat to keep it in place. It looks very much like something one's mother might do (Martin, 1998, p. 498).

These young children have already internalized the rule that when wearing a dress, even a dress-like tunic with leggings, they must constantly monitor their decorum-who knows what immodesty might otherwise result, what dirt (metaphorically and literally) might cling.

The linking of dirt and immorality is a robust phenomenon historically in the industrialized North and West. In the schools and playgrounds of nineteenth-century Britain and the United States, education about physical cleaning was meant to introduce moral cleanliness as well, especially for the immigrant and working class (Gagen, 2000, 225; Tomes, 1998). For girls in general, though, education about keeping clean and tidy was not just important for physical hygiene, it also helped them to "adopt particular [feminine] ways of carrying and presenting their bodies" (Gagen, 2000, p. 225).

Returning to the present day, sociologist Thorne (1993) documents gender norms in the play of American children at the elementary school level. Of particular relevance is her discussion of "cooties," and other "pollution rituals" - concerns that are especially prevalent, she notes, in children ages six to nine. The term "cooties" here refers to invisible germs that children play at passing on to others through touch, or more pointedly, that children play at avoiding by ostracization of those assigned (usually against their will) as carriers. Thorne's observations, taken from field work in the late 1970s and early 1980s at schools in Michigan and California, show that girls are far more likely than boys to be associated with cooties and to be ostracized as carriers of cooties. The clear message is that, unlike boys, girls need to guard against these and other forms of pollution. "Girls as a group are treated as an ultimate source of contamination" (p. 74). While individual boys are sometimes also so marked, in these cases, she notes, it is the boy's ethnicity or physical ability that is used to set him up as a source of pollution, rather than his gender, per se. She also documents a common pattern in this research, namely that boys, more often than girls, played outdoors.

On a final note, regarding research about girls policing their own hygiene, it seems unlikely to be a coincidence that among sufferers of Obsessive Compulsive Disorder, hand washing and cleaning compulsions are far more common in women than men (Bogetto, Venturello, Albert, Maina, \& Ravizza, 1999; Castle \& Groves, 2000; Lensi et al., 1996; Minichiello, Baer, Jenike, \& Holland, 1990; Rachman \& Hodgson, 1980).

\section{Women, auto-immune disorders, and depression}

As noted earlier, there are a number of immunological health outcomes in adults that attention to gender and hygiene in children might help explain: Women far more than men suffer from asthma, allergies, and a number of auto-immune disorders, such as IBD, Crohn's, rheumatoid arthritis, multiple-sclerosis, Grave's disease, and Lupus (see, for example, Jacobson, Gange, Rose, \& Graham, 1997; Walsh \& Rau, 2000). Insofar as depression can be tied to hygiene, then the alarming fact of women's rates of depression might also fall, at least partially, under the explanatory umbrella of the augmented hygiene hypothesis.

Beginning with the case of asthma, age complicates the issue in a way that is consistent with my augmented hygiene hypothesis regarding the gender socialization of children. Before puberty, boys have higher rates of asthma than girls (Johnson, Peterson, \& Ownby 1998; Osman, 2003). After puberty, the sex difference reverses, with women having higher rates than men. Osman (2003) reports that the reasons for the age-link remain unclear. As mentioned above, there are a number of competing biomedical explanations for the "over-active" immune systems of women relative to men (for a critical discussion of the sexism of some of these explanations see Bird \& Rieker, 2008; Howes, 2007), however, there are no accepted explanations available (biomedical or otherwise) for the over-active immune systems of boys relative to girls. If my augmented hypothesis is right, it is likely that there is a critical period involved, a developmental period during which the immune system, properly exposed to potential allergens, responds with asthmatic symptoms, and after which shows a "settling effect." Those children, typically boys, properly exposed during the critical period, respond with asthmatic symptoms early on, but then their symptoms abate. Those children, typically girls, not exposed during the critical period, respond with asthmatic symptoms later, and for the rest of their lives.

In fact, a critical period of just this sort was found in Ownby et al. (2002), the study referred to above, that showed that having two or more pets in the home at infancy protected children against allergies at six years of age. The positive effect was not found if the pets were introduced later than infancy. And, in what the authors note as a "puzzling" aside, the protective effect of pets in the home was significantly more marked for boys than girls (Ownby et al., 2002, 970).

That women are over-represented among the clinically depressed across numerous cultures is, as reported above, another well-supported finding (see Kuehner, 2003, for a review of this literature). Debates continue about the causal explanation of this sex difference. Altemus (2006) believes that the robust crosscultural effect requires a biomedical explanation appealing to, for 
example, estrogen, or genetics, though admits that such an explanation has proven elusive (p. 364). Completing a meta-analysis of the literature, Kuehner argues for the importance of linking biological arguments with appeals to well documented social "risk factors":

Consistently, intrapsychic and psychosocial gender role related risk factors have been identified which may contribute to the higher depression risk in women. Gender role aspects are also reflected in endocrine stress reactions and possibly influence associated neuropsychological processes (Kuehner, 2003, 169).

A hygiene hypothesis that takes into account the differential gender role socialization of boys and girls can provide the missing link between the biological and social risk factors called for by Kuehner.

\section{Increasing the empirical adequacy of the hygiene hypothesis}

Following Krieger (2003), regarding the importance of clarity when using the terms "gender" and "sex" in epidemiological studies, I have shown that, insofar as the hygiene hypothesis assigns a plausible causal role for hygiene practices in a host of immune-related illnesses, then it makes sense that gendered, that is, socially-mediated, standards of cleanliness that are generally higher for girls than boys, can differentially affect physiological processes of exposure to allergens, bacteria, and parasites, a difference in exposure that results in sex differences in morbidity rates in a host of immune-related illnesses (including, perhaps depression) in adulthood.

My use of cautionary phrases such as "generally higher for girls than boys," is meant to indicate a respect for the complexity of gender categories as they are interwoven in the hygiene story with categories of ethnicity and socio-economic status. While I attend to these latter categories, at least in terms of nationality and urbanization, more analysis on these fronts is needed to fill in the explanatory picture.

The hygiene hypothesis is currently well-supported, though not without competitors, and, as I have noted, there remains a "puzzle" concerning the interaction of age and sex differences in rates of allergies, and some auto-immune disorders. I have argued that feminist-informed research regarding the differential socialization patterns of girls and boys and their relationship to dirt and germs suggests a solution to the puzzle.

Thinking in terms of gender differences in hygiene also helps identify new relevant sources of evidence for the hygiene hypothesis and opens up further avenues for study. While epidemiologists and immunologists who study the hypothesis have not yet linked gendered norms of cleanliness to morbidity rates for allergies, asthma, immune disorders more generally, and/or depression, there are some epidemiological studies of children that mention gender differences in exposure to dust, dirt, and germs and these studies, not previously believed to be relevant, could be used to provide support for and point towards the further development of the hygiene hypothesis.

Eating dirt, or geophagia, is a very reliable way to ingest microorganisms, and in a study from rural Guinea that examined the ingestion of parasites via geophagia, boys under the age of ten are significantly more likely than girls to be infected by these parasites (Glickman, Camara, Glickman, \& McCabe, 1999). Studies of children with bloodstream infection (BSI) from Acinobacter species, show similar results (Segal, Zaoutis, Kagen, Shah, \& Samir, 2007). For adults in the industrialized North and West, exposure to Acinobacteria is generally associated with a hospital stay. New research has shown that in children, the pattern is different - for children, infection is significantly more likely to be developed in the home, and by patients who are male. That is, consistent with my augmented hypothesis, under the gendered supervision of parents in home settings, more boys than girls are exposed to this bacteria (Segal et al., 2007).

Consider also studies of the transmission of Ascaris lumbricoides (a harmful intestinal roundworm) among rural populations in Southern Ethiopia (Vechiatto, 1997). The transmission route typically involves "ingestion of infective eggs from soil contaminated with human feces or uncooked vegetables contaminated with soil containing infective eggs" (Vechiatto, 1997, p. 241). In Southern Ethiopia, homes typically have dirt floors, infants are often accompanied by domestic dogs throughout the day, and livestock are brought into homes at night. The dogs and livestock as well as the dirt floors are all sources of the eggs. Children are the primary victims of roundworm infection. At one clinic, " $70 \%$ of all outpatients treated for helminthiases [intestinal parasites] were children under fourteen years of age" (p. 245), with infection rates highest among one- to four-year-olds. Of note here is the sex difference: $20.5 \%$ of males in this age group had Ascariasis infection, as opposed to only $13.5 \%$ of females. The researchers remarked that this gap closes in later ages, e.g., 5-14 year olds, where rates lower -in males to $8.9 \%$ and females to $11.3 \%$ - "making it difficult to establish statistically significant sex differences in worm infection" (p. 246).

However, the change across age groups might be explained by differential hygiene expectations for boys and girls (more on the cross-cultural strength of these expectations, below). Infants, both male and female, are likely to be under greater parental supervision than are older children, and for females more than males, greater supervision is likely to come with increased restrictions on how and where they play. Perhaps these gendered facets of parental supervision explain the fact that in the one- to four-year olds, significantly fewer girls than boys were found to have parasites. In addition, the reported decrease in parasitic load with age might be similar to the decrease in asthma rates with age that is reported in boys and girls in countries in the industrialized North and West. Again, a critical period for exposure to the relevant parasites might be at work, disadvantaging those children, typically girls, who have fewer opportunities for exposure.

If the modalities of exposure to harmful micro-organisms such as Acinetobacter species and the Ascaris lumbricoides parasite are similar to those for the more helpful micro-organisms that calm over-active immune systems (such as M. Vaccae, and the Trichuris suis whip worm) then epidemiological studies like these, attending to gendered norms of cleanliness, could serve as further sources of evidence in support of the hygiene hypothesis. If increased hygiene negatively affects immune health, and immune health differs by sex (as research shows it does), then we should see sex differences in the morbidity rates for these illnesses. In this study, such sex differences are evident.

The epidemiological research in rural Guinea, and Southern Ethiopia, cited above, introduces another avenue of study that could provide evidence for the hygiene hypothesis. Research undertaken outside the industrialized North and West, provides the opportunity for a number of cross-cultural, natural experiments.

The first sort of experiment would evaluate whether the gender norms that place higher standards of cleanliness on girls than boys holds across different cultures. Some of the sociological and anthropological research on gendered norms of cleanliness in the more rural parts of the global South and East suggests that this is the case.

In her field work in Bengali, India, anthropologist Lamb found that women and girls are expected to bathe more often than men and boys-expectations that are related to views of women and girls as naturally dirtier than men and boys (Lamb, 2005, p. 213). For these women and girls, the practice of bathing, often twice or more 
times daily, consists mostly in a ritual rinsing with water, rather than wringing one's hands with anti-bacterial soap, or guarding against cooties, but the gender differences in cleanliness here clearly run parallel to the purity notions associated with femininity in the North and West.

In the Caribbean country of Guyana, sociological research on parental socialization preferences showed that parents rated neatness and cleanliness as "more desirable for girls [than boys] in all age groups" (Wilson, Wilson, \& Berkeley-Caines, 2003, 217).

One difference between the activities of children in the industrialized North and West and children in the more rural settings of the South and East is that in the latter societies, children are typically given far greater freedom from parental supervision through their assigned chores, such as minding cattle and sheep (Punch, 2000). It remains to be examined whether and how this freedom affects standards of hygiene for boys and girls. One might expect that here, girls are under less parental supervision and have more freedom to play in the dirt. Are they also more healthy, immunologically-speaking, as adults? Research on this question would be helpful.

A second kind of natural experiment involves examining whether those studies of the rural South and East that reported higher levels of ingestion of micro-organisms in boys, also found this to be correlated with those boys having a lower incidence of allergies, asthma, IBD, and depression. We already know that the incidence and prevalence of these diseases is lower in the more rural nations of the South and East, relative to the industrialized North and West, but, within the former populations, are the same gender differences found there, as feminists have found in the North and West? Insofar as the gendered socialization patterns that have been well-identified in the industrialized North and West continue in the nonindustrialized, primarily rural settings of the South and East, we can expect that there will be sex differences in the relevant morbidity rates.

A second kind of natural experiment involves examining whether those studies of the rural South and East that reported higher levels of ingestion of micro-organisms in boys, also found this to be correlated with those boys having a lower incidence of allergies, asthma, IBD, and depression. We already know that the incidence and prevalence of these diseases is lower in the more rural nations of the South and East, relative to the industrialized North and West, but, within the former populations, are the same gender differences found there, as feminists have found in the North and West? Insofar as the gendered socialization patterns that have been well-identified in the industrialized North and West continue in the nonindustrialized, primarily rural settings of the South and East, we can expect that there will be sex differences in the relevant morbidity rates.

One study comes close to confirming this expectation. Researching allergies among the Hiwi settlements of Venezuela, anthropologists Hurtado, et al. noted that, consistent with the hygiene hypothesis, these populations had lower rates of allergies than are typically found in populations of the industrialized nations of the North and West (Hurtado, Hill, Arenas de Hurtado, \& Rodriguez, 1997). They also note that Hiwi girls spend significantly more time than do boys engaging in "grooming behaviors," and that these behaviors "serve to eliminate ectoparasites" (p. 63). What they did not note in their study was whether there were any sex differences in parasite exposure between Hiwi boys and girls, though the grooming behavior suggests there is. They also did not note whether there were any differences in incidence and prevalence of allergies between Hiwi girls and boys, women and men, though differences in parasite exposure between Hiwi boys and girls would predict higher incidence and prevalence of allergies among girls. The presentation of their data suggests that they have this information available (they present data comparing Hiwi girls and women to girls and women from Western populations, for example).

The point here is that their cross-cultural analysis of the relationship between the Hiwi's higher rates of exposure to parasites and decreased incidence and prevalence of allergies, relative to populations in the North and West, does indeed provide support for the hygiene hypothesis. However, had the researchers also documented more explicitly the implied relationship between the Hiwi boys' higher rates of exposure to parasites and decreased incidence and prevalence of allergies, relative to Hiwi girls, then that evidence could have provided yet another layer of support for the hygiene hypothesis.

Of course there are at least two explanations for why they did not offer this additional evidence. Perhaps they looked for the sex differences in incidence and prevalence of allergies within the Hiwi children and found none. Given their hygiene hypothesis, and the differences they found in grooming behaviors between girls and boys, they would have needed to account for, or at least acknowledge, this discrepancy. Because no such account was forthcoming in their published study, the more likely explanation is that they were insufficiently attentive to the effect of childhood gender socialization on hygiene and ultimately on morbidity rates. Paying attention to gender differences in social expectations of cleanliness can provide hygiene hypothesis researchers with additional sources of evidence that might otherwise go ignored.

It is important to note that in nations of the industrialized North and West it is not just sanitation policies and practices that have decreased children's exposure to micro-organisms. Sociologists who study play behaviors have noticed a marked decrease in the rates at which both boys and girls play outdoors in the dirt. This change in play pattern is yet another evidential link that could be used to support the hygiene hypothesis-a link that becomes relevant when gender roles are taken into consideration.

In a study of American playgrounds in the United States, Frost (2007) notes that, increasingly, children in the US find "their places for play dominated by manufactured equipment, regimented games, and paved surfaces" and he ties this trend directly to support for the hygiene hypothesis (p. 24). He also notes that public schools are, increasingly, deleting recess, and that even public playgrounds are being visited less often as parents fear injury and violence.

Recall that the hygiene hypothesis is used to explain the increased rates of immune-related morbidity in populations of the industrialized North and West, as a whole. The morbidity rates at issue have increased for both women and men, girls and boys. Given the relatively recent decrease in access to outdoor play, a number of natural experiments suggest themselves once gender roles are made salient. Especially in the suburbs of the industrialized North and West, boys are more likely to have been affected by these restrictions in the type and place of play than are girls. In these populations, have the relevant morbidity rates increased more markedly among boys than girls? One would expect so if my augmented hygiene hypothesis is correct. These are just a few of the natural experiments on the hygiene hypothesis that become obvious once gender socialization is made salient.

\section{Conclusion}

As it stands, the hygiene hypothesis already enriches and indeed moves beyond reductionistic biomedical approaches to immunological illnesses, by attending to complex environmental and social factors such as sanitation and hygiene standards. I have argued that insofar as the hygiene hypothesis successfully identifies standards of hygiene and sanitation as mediators of immune health, 
then introducing a feminist analysis of the gendered standards of cleanliness in children adds important empirical resources to the explanatory picture.

Having conducted an interdisciplinary review of feminist research on the gender socialization of children, I have shown that insofar as social preferences for cleanliness are enforced more aggressively for girls than boys, this gender difference leaves girls with lower rates of exposure than boys, to an array of microorganisms. Attention to differences within gender categories, such as nationality, and urbanization, make clear that the gendered pattern is robust.

My augmented hygiene hypothesis helps fill in some of the explanatory gaps in our current understanding of why it is that in industrialized nations of the North and West, at least, women are more likely than men to suffer from allergies, asthma, auto-immune diseases, and, perhaps, depression. It also responds to a number of outstanding puzzles in the hygiene hypothesis research, makes available new sources of evidence, and suggests designs for a number of cross-cultural and other natural experiments.

\section{Acknowledgements}

The author gratefully acknowledges Kristin Barker, Sharon Crasnow, Jonathan Kaplan, Kristen Intemann, and two anonymous referees for their helpful comments on earlier drafts of this paper. Thanks also to Meghan Kahnle for her research assistance.

\section{References}

Altemus, M. (2006). Sex differences in depression and anxiety disorders: potential biological determinants. Hormones and Behavior, 50, 534-538.

Ayuso-Mateos, J. L., et al. (2001). Depressive disorders in Europe: prevalence figures from the ODIN study. British Journal of Psychiatry, 179, 308-316.

Barker, K. (2005). The Fibromyalgia story: Medical authority and women's worlds of pain. Philadelphia: Temple University Press.

Beeson, P. B. (2004). Age and sex associations of 40 autoimmune diseases. American Journal of Medicine, 96(5), 457-462.

Bird, C. E., \& Rieker, P. P. (1999). Gender matters: an integrated model for understanding men's and women's health. Social Science E Medicine, 48, 745-755.

Bird, C. E., \& Rieker, P. P. (2008). Gender and health: The effects of constrained choices and social policies. Cambridge: Cambridge University Press.

Bogetto, F., Venturello, S., Albert, U., Maina, G., \& Ravizza, L. (1999). Gender-related clinical differences in obsessive-compulsive disorder. European Psychiatry, 14 434-441.

Caldera, Y. M., Huston, A. C., \& O'Brien, M. (1989). Social interactions and play patterns of parents and toddlers with feminine, masculine, and neutral toys. Child Development, 60, 70-76.

Castle, D. J., \& Groves, A. (2000). Heart of the matter: the internal and external boundaries of obsessive-compulsive disorder. Australian and New Zealand Journal of Psychiatry, 34, 249-255.

Chisholm, D., et al. (2004). Reducing the global burden of depression: populationlevel analysis of intervention cost-effectiveness in 14 world regions. British Journal of Psychiatry, 184, 393-403.

DeSai, H., \& Gupta, P. (2005). Increasing incidence of Crohn's disease in India: is it related to improved sanitation? Indian Journal of Gastroenterology, 24, 23-24.

Elliott, D. E., Summers, R. W., \& Weinstock, J. V. (2007). Helminths as governors of immune-mediated inflammation. Int Journal of Parasitology, 37(5), 457-464.

Epstein, S. (2007). Inclusion: The politics of difference in medical research. Chicago: University of Chicago.

Erb, K. (2009). Can helminths or helminth-derived products be used in humans to prevent or treat allergic diseases? Trends in Immunology, 30(2), 75-82.

Frost, J. L. (2007). Genesis and evolution of American play and playgrounds. In D. J. Sluss, \& O. S. Jarrett (Eds.), Investigating play in the 21st century. Play and culture studies, Vol. 7 (pp. 3-31). New York: University Press of America.

Gagen, E. A. (2000). An example to us all: child development and identity construction in early 20th-century playgrounds. Environment and Planning A, 32 (4), 599-616.

Glickman, L. T., Camara, A. O., Glickman, N. W., \& McCabe, G. P. (1999). Nematode intestinal parasites of children in rural Guinea, Africa: prevalence and relationship to geophagia. International Journal of Epidemiology, 28, 169-174.

Hankin, B. L., \& Abramson, L. Y. (2001). Development of gender differences in depression: an elaborated cognitive vulnerability-transactional stress theory. Psychological Bulletin, 127(6), 773-796.

Horwitz, A. V., \& Wakefield, J. C. (2007). The loss of sadness: How psychiatry transformed normal sorrow into depressive disorder. New York: Oxford University Press.
Howes, M. (2007). Maternal agency and the immunological paradox of pregnancy. In Harold Kincaid, \& Jennifer McKitrick (Eds.), Establishing medical reality: Essays in the metaphysics and epistemology of biomedical science (pp. 179-198). Netherlands: Springer

Hurtado, A., Hill, K., Arenas de Hurtado, I., \& Rodriguez, S. (1997). The evolutionary context of chronic allergic conditions: the Hiwi of Venezuela. Human Nature, 8 (1), 51-75.

Jackson, M. (2006). Allergy: The history of a modern malady. London: Reaktion Books. Jacobson, D. L., Gange, S. J., Rose, N. R., \& Graham, N. M. (1997). Epidemiology and estimated population burden of selected autoimmune diseases in the United States. Clinical Immunology and Immunopathology, 84(3), 223-243.

Johnson, C. Peterson, E \& Ownby, D. R. (1998). Gender differences in total and allergenspecific immunoglobulin $\mathrm{E}$ (IgE) concentrations in a population-based cohort from birth to age four years. American Journal of Epidemiology, 147, 1145-1152.

Kilpeläinen, M., Terho, E. O., Helenius, H., \& Koskenvuo, M. (2000). Farm environment in childhood prevents the development of allergies. Clinical and Experimental Allergy, 30(2), 201-208.

Krieger, N. (2003). Genders, sexes, and health: what are the connections and why does it matter? International Journal of Epidemiology, 32, 652-657.

Kuehner, C. (2003). Gender differences in unipolar depression: an update of epidemiological findings and possible explanations. Acta Psychiatrica Scandinavica, 108, 163-174.

Lamb, S. (2005). The politics of dirt and gender: body techniques in Bengali India. In A. Masquelier (Ed.), Dirt, undress and difference: Critical perspectives on the body's surface (pp. 213-232). , Bloomington: Indiana University Press.

Lanphear, B., \& Roghmann, K. (1997). Pathways of lead exposure in urban children. Environmental Research, 74, 67-73.

Lensi, P., Cassano, G. B., Correddu, G., Ravagli, S., Kunovac, J. L., \& Akiskal, H. S. (1996). Obsessive - compulsive disorder. Familial developmental history, symptomatology, comorbidity and course with special reference to genderrelated differences. British Journal of Psychiatry, 169, 101-107.

Lowry, C. A., Hollis, J. H., de Vries, A., Pan, B., Brunet, L. R., Hunt, J. R. F., et al. (2007) Identification of an immune-responsive mesolimbocortical serotonergic system: potential role in regulation of emotional behavior. Neuroscience, 146, 756-772.

McDade, T. W., Rutherford, J., Adair, L., \& Kuzawa, C. W. (2009). Early origins of inflammation: microbial exposures in infancy predict lower levels of C-reactive protein in adulthood. Proceedings of Royal Society of Britain, Biological Sciences, Published online 9 December 2009.

Martin, K. A. (1998). Becoming a gendered body: practices of preschools. American Sociological Review, 63(4), 494-511.

Maziak, W., Behrens, T., Brasky, T. M., Duhme, H., Rzehak, P., Weiland, S. K., et al. (2003). Are asthma and allergies in children and adolescents increasing? Results from ISAAC phase I and phase III surveys in Munster, Germany. Allergy, 58, 572-579.

Minichiello, W. E., Baer, L., Jenike, M. A., \& Holland, A. (1990). Age of onset of major subtypes of obsessive-compulsive disorder.Journal of Anxiety Disorders, 4,147-150.

Nolen-Hoeksema, S. (2001). Gender differences in depression. Current Directions in Psychological Science, 10(3), 173-176.

O'Brien, M. E., et al. (2004). SRL172 (killed Mycobacterium vaccae) in addition to standard chemotherapy improves quality of life without affecting survival, in patients with advanced non-small-cell lung cancer: phase III results. Annals of Oncolology, 15, 906-914.

Osman, M. (2003). Therapeutic implications of sex differences in asthma and atopy: community child health, public health, and epidemiology. Archives of Disease in Childhood, 88(7), 587-590.

Ownby, D., Johnson, C., \& Peterson, E. L. (2002). Exposure to dogs and cats in the first year of life and risk of allergic sensitization at 6 to 7 years of age. JAMA, 288 (8), 963-972.

Pomerleau, A., Bolduc, D., Malcuit, G., \& Cossette, L. (1990). Pink or blue: environmental gender stereotypes in the first two years of life. Sex Roles, 22(5-6), $359-367$.

Punch, S. (2000). Children's strategies for creating playspaces: negotiating independence in rural Bolivia. In Sarah Holloway, \& Gill Valentine (Eds.), Children's geographies: Playing, living, learning. London: Routledge.

Rachman, S., \& Hodgson, R. (1980). Obsessions and Compulsions. Englewood Cliff, NJ: Prentice Hall.

Richardson, S. S. (2008). When gender criticism becomes standard scientific practice: the case of sex determination genetics. In L. Schiebinger (Ed.), Gendered innovations in science and engineering (pp. 22-42). Palo Alto: Stanford University Press.

Ricklin-Gutzwiller, M. E., et al. (2007). Intradermal injection of heat- killed Mycobacterium vaccae in dogs with atopic dermatitis: a multicentre pilot study. Veterinary Dermatology, 18, 87-93.

Rook, G. A. W., \& Lowry, C. A. (2008). The hygiene hypothesis and psychiatric disorders. Trends in Immunology, 29(4), 150-158.

Segal, S., Zaoutis, T., Kagen, Shah, J., \& Samir, S. (2007). Epidemiology of and risk factors for Acinetobacter species bloodstream infection in children. The Pediatric Infectious Disease Journal, 26(10), 920-926.

Shirley, M. (1938). Common content in the speech of preschool children. Child Development, 9(4), 333-346.

Sikes, P. (1991). "Nature took its course"? Student teachers and gender awareness. Gender and Education, 3(2), 145-162.

Spiga, F., Lightman, S. L., Shekar, A., \& Lowry, C. A. (2006). Injections of Urocortin 1 into the Basolateral Amygdala induce anxiety-like behavior and c-Fos expression in brainstem serotonergic neurons. Neuroscience, 138, 1265-1276. 
Strachen, D. (1989). Hay fever, hygiene, and household size. British Medical Journal, 299, 1259-1260.

Summers, R. W., Elliott, D. E., Urban, J. F., Jr., Thompson, R., \& Weinstock, J. V. (2005). Trichuris suis therapy in Crohn's disease. Gut, 54(1), 87-90.

Thorne, B. (1993). Gender play: Girls and boys in school. New Brunswick, NJ: Rutgers University Press.

Tomes, N. (1998). The Gospel of germs: Men, women, and the microbe in American life. Cambridge, MA: Harvard University Press.

Vechiatto, N. (1997). 'Digestive worms': ethnomedical approaches to intestinal parasitism in southern Ethiopia. In Marcia Inhorn, \& Peter Brown (Eds.), The anthropology of infectious disease: International health perspectives (pp. 241-266). Amsterdam: Gordon and Breach Publishers.
Walsh, S. J., \& Rau, L. M. (2000). Autoimmune diseases: a leading cause of death among young and middle- aged women in the United States. American Journal of Public Health, 90(9), 1463-1466.

Wilson, L. C., Wilson, C. M., \& Berkeley-Caines, L. (2003). Age, gender and socioeconomic differences in parental socialization preferences in Guyana. Journal of Comparative Family Studies, 34, 213-227.

Zuany-Amorim, C., et al. (2002). Suppression of airway eosinophilia by killed Mycobacterium vaccae-induced allergen-specific regulatory T-cells. Nature Medicine, 8, 625-629.

Zvidi, I., Hazazi, R., Birkenfeld, S., \& Niv, Y. (2008). The prevalence of Crohn's disease in Israel: a 20-year survey. Digestive Diseases and Sciences, 54(4), $848-852$. 